\title{
Facing the challenges of computational target prediction
}

\author{
Karen T Schomburg*, Matthias Rarey \\ From 9th German Conference on Chemoinformatics \\ Fulda, Germany. 10-12 November 2013
}

To which proteins does a compound bind? Is it selective or promiscuous? These are questions which can be answered by inverse virtual screening, which identifies potential targets for a molecule of interest. Experimental screening of a molecule on thousands of targets is costly and elaborate. Contrarily, structure-based computational methods are only limited by the availability of 3D structures, rendering them an important complement to experimental methods.

Our inverse screening method XxirT combines triangle descriptor matching [1] with a new ranking approach, considering a reference score for each pocket. A precalculated bitmap encoding of the descriptors and an efficient design of a database for $3 \mathrm{D}$ protein structures allows a rapid screening of thousands of protein-ligand complexes with a query compound.

Classical protein-ligand scoring functions are not capable of inter-target score comparison, since the absolute values are target-dependent. Therefore, in inverse virtual screening, a major problem is the design of a ranking scheme allowing the comparison of target scores with respect to one query compound [2]. A lack of available data for statistical evaluation of the ranking capability further complicates the task. Data sets mostly contain positive hits, e.g. binding affinities for one molecule to several proteins while lacking negative data points, such as 'the molecule does not bind to this protein'. As a basis for statistical evaluation of our new inverse screening concept, we introduce a dataset consisting of a ligand set of approved drugs and the scPDB target database [3]. Drugs are well qualified for use in a method evaluation dataset, as they are well tested and had to pass selectivity standard tests to get approved. Therefore, their targets are comparably well-characterized, allowing a classification into true positives and true negatives. This approach

\footnotetext{
* Correspondence: schomburg@zbh.uni-hamburg.de Center for Bioinformatics, University of Hamburg, Hamburg, Germany
}

is the first that evaluates a structure-based inverse screening method on a systematic statistical test.

Published: 11 March 2014

\section{References}

1. Schlosser J, Rarey M: Beyond the Virtual Screening Paradigm: StructureBased Searching for New Lead Compounds. J Chem Inf Model 2009, 49:800-809.

2. Kellenberger E, Foata N, Rognan D: Ranking Targets in Structure-Based Virtual Screening of Three-Dimensional Protein Libraries: Methods and Problems. J Chem Inf Model 2008, 48:1014-1025.

3. Meslamani J, Rognan D, Kellenberger E: sc-PDB: a database for identifying variations and multiplicity of 'druggable' binding sites in proteins. Bioinformatics 2011, 27:1324-1326.

doi:10.1186/1758-2946-6-S1-O3

Cite this article as: Schomburg and Rarey: Facing the challenges of computational target prediction. Journal of Cheminformatics 2014 6(Suppl 1):O3.

\section{Publish with ChemistryCentral and every scientist can read your work free of charge \\ "Open access provides opportunities to our colleagues in other parts of the globe, by allowing anyone to view the content free of charge." \\ W. Jeffery Hurst, The Hershey Company. \\ - available free of charge to the entire scientific community \\ - peer reviewed and published immediately upon acceptance \\ - cited in PubMed and archived on PubMed Central \\ - yours - you keep the copyright \\ Submit your manuscript here: \\ http://www.chemistrycentral.com/manuscript/}

